\title{
Using the language of science
}

\author{
The scientific literature, as literature, is much despised, and rightly. Should not the turning of another \\ year be an occasion when its authors resolve to mend their ways?
}

THIS is the season when rash people declare their ambitions for the year ahead, sometimes recklessly in public. Secretly, a person may say to himself, or to his spouse, that he will cure some kind of cancer in 1989. It is natural, on these occasions, that there should be others who insist, self-interestedly no doubt, that the bravest ambitions are, by definition, the most likely to attain other goals as well.

What follows is a self-interested plea that contributors (and would-be contributors) to Nature should change their ways and, if about to cure a kind of cancer or to show the mechanism of high-temperature superconductivity, should also write so as more clearly to communicate what they have to say to at least some part of their audience. If this appeal should seem to be a dressed-up plea on behalf of the public interest, it will of course be quickly dismissed as such.

To say that present performance is appalling would be wrong; there are remarkably few complaints. Readers who write in are so much more often zealous in their regard for the proprieties of priority, or so anxious that a date should be correct, but so uncaring about the chances that their own protests will be understood, that one is bound to ask whether people who read for understanding habitually read something else instead, perhaps the back of a breakfast-cereal package.

Yet, we all believe, research has a simple structure. There is what is called a 'body of understanding' which, once understood, can be taught to undergraduates. Research is the process of adding to this structure elements of discovery which are occasionally simplifying, but which are more often complications. So do we not have an obligation to begin by reminding everybody of the startingpoint, that which is already understood? "I will begin with an arresting statement that everybody can understand" should be the first of the new year's resolutions.

The second should be a resolution that the conclusion should be a declarative statement and that it should appear at least twice - at the end, where it logically belongs, and once somewhere else, preferably at the beginning. The logic is that scientific articles are different from detective stories, whose readers may enjoy suspense. Busy people, by contrast, expect that what they read will tell them in advance why they should take the trouble. And it will not for most readers suffice to be told that "the implications for the mechanism of high-temperature superconductivity will be explored". Readers want to know what new there is to say about it.

The most serious enemy of clarity in the literature is the reverence that data command, whence a third precept. The difficulty is that any substantial programme of research is always over-flush with information; there are always numbers that cannot be quoted for lack of space, but which might be quoted if only journals were more generous. The result is that most contributions to the published literature contain more information than is necessary to support their conclusions, or even to permit mechanical replication. That is why there is the strongest possible case for not publishing information irrelevant to the intended conclusion.

But is that not an invitation to bias? If an author is encouraged not to publish all the numbers he has collected, but only those which support his case, will not the literature quickly fill with spurious arguments? That question is simple sophistry. Everybody who makes a telling point in print knows more about the real world than can be gleaned from his publication. But it is possible to tell the difference between partial and balanced arguments by the ways in which people cite their data. The strong cases are those which cite contradictory data - and then give the reasons why they do not matter. Briefly, the fourth rule is that data on their own are but numbers; they become meaningful to ordinary mortals only when their authors evidently reflect upon them.

Concepts are a further complication. The conventional wisdom is that science has been carried beyond ordinary human ken by the intricacy of its intellectual fabric. Yesterday's science may be teachable to undergraduates, but today's cannot be told in in language that makes sense even to others working in the field. Can that be so? Or is it possible that the belief is a modern version of the old seventeenth-century device of concealing discoveries in anagrams or, worse, a conseqence of idleness? Either way, a valuable fifth precept for intending authors would be a resolve never to make a general statement so general that readers have to cudgel their brains to know how it relates to what they know already.

Language is the next distraction. The opinion that those who practise science cannot be expected also to have a flair for knowing how sentences are constructed and strung together is held by many, but not all, of those who earn their livings as researchers. The exceptions include many who say that there is nothing to the use of language that cannot be picked up by reading novels at weekends or even, since time is short, on airplane journeys. So, sadly, it should be plainly understood that an indifference to the way in which language is used must be equated with an indifference to meaning: a person holding that the verbs "to mitigate" and "to militate against" are in some way equivalent is no better than a person who professes not to care whether water naturally runs "uphill" or "downhill".

Naturally it is a serious matter to assert that some, perhaps many, of those who contribute to the literature of science, zealous though they may be about their numbers, are indifferent to the meaning of what they say in words. It is as if to accuse them of some acknowledged professional misdemeanour, plagiarism for example, or the deliberate misrepresentation of what data mean. But by what criteria can these misdemeanours otherwise be excused? Not to care about meaning is no better when words are in dispute. Yet the misuse of words is the most common fault in the science journals.

Sheer ugliness is evidently less grave a crime, but is so common that the question must arise of whether it is deliberate, and if so why. The innuendo is simply dealt with: ugliness is not often a subterfuge, but is more often mistaken for a mark of precision. If one molecule "binds" another, it is surely behaving much more specifically than merely "binding to" the other. The "ATP-dependent-protein kinase" cannot be just another phosphorylating agent. One obvious difficulty is that these packaged verbal constellations are often ambiguous. (Where should the hyphens go in "ATP-dependent..."?) A less obvious, but potentially more serious, difficulty is that many readers cannot stomach these constructions - and read something else instead.

That is why, if there are to be new year's resolutions for 1989 other than the curing of this or that kind of cancer, it would be invaluable if they could include some acknowledgement of the literary problems of the scientific literature. Why not, indeed, do both - cure cancer and let people read about it? John Maddox 